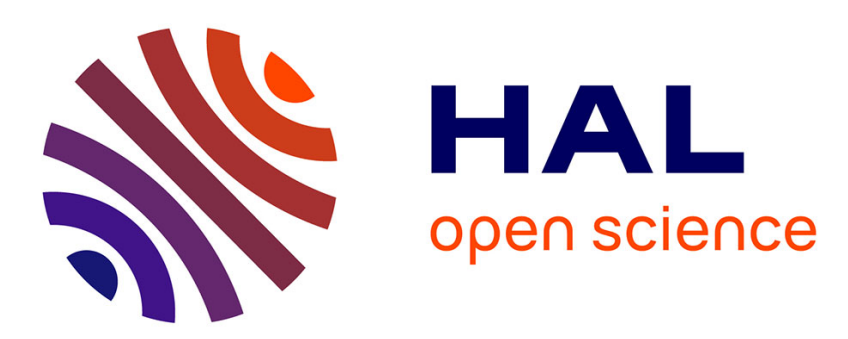

\title{
Powder preparation and UV absorption properties of selected compositions in the CeO2-Y2O3 system
}

Franck Tessier, François Cheviré, Francisco Muñoz, Odile

Merdrignac-Conanec, Roger Marchand, Michel Bouchard, Christophe

Colbeau-Justin

\section{To cite this version:}

Franck Tessier, François Cheviré, Francisco Muñoz, Odile Merdrignac-Conanec, Roger Marchand, et al. Powder preparation and UV absorption properties of selected compositions in the CeO2-Y2O3 system. Journal of Solid State Chemistry, 2008, 181 (5), pp.1204-1212. 10.1016/j.jssc.2008.02.034 . hal-00400670

\section{HAL Id: hal-00400670 \\ https://hal.science/hal-00400670}

Submitted on 16 Feb 2016

HAL is a multi-disciplinary open access archive for the deposit and dissemination of scientific research documents, whether they are published or not. The documents may come from teaching and research institutions in France or abroad, or from public or private research centers.
L'archive ouverte pluridisciplinaire HAL, est destinée au dépôt et à la diffusion de documents scientifiques de niveau recherche, publiés ou non, émanant des établissements d'enseignement et de recherche français ou étrangers, des laboratoires publics ou privés. 


\title{
Powder preparation and UV absorption properties of selected compositions in the $\mathrm{CeO}_{2}-\mathrm{Y}_{2} \mathrm{O}_{3}$ system
}

Franck Tessier ${ }^{\mathrm{a}, *}$, François Cheviréa, Francisco Muñoz ${ }^{\mathrm{a},{ }^{* *}}$, Odile Merdrignac-Conanec ${ }^{\mathrm{a}}$, Roger Marchand $^{\mathrm{a}}$, Michel Bouchard ${ }^{\mathrm{b}}$, Christophe Colbeau-Justin ${ }^{\mathrm{b}}$.

a UMR CNRS 6226 "Sciences Chimiques de Rennes", équipe "Verres et Céramiques", Université de Rennes 1, 35042 Rennes cedex, France

*Franck.Tessier@univ-rennes1.frＦax:+33223235683

** present address: Instituto de Cerámica y Vidrio (CSIC), Kelsen 5, 28049 Madrid (Spain)

b Laboratoire d'Ingénierie des Matériaux et des Hautes Pressions, CNRS UPR 1311, Université Paris 13, 99 Avenue J. B. Clément, 93430 Villetaneuse, France

\section{Keywords}

Modified ceria, Solid solution, Optical properties, UV absorbers

\begin{abstract}
Several approaches have been investigated to prepare fluorite-type compositions within the (1-x) $\mathrm{CeO}_{2}-\mathrm{x} \mathrm{YO}_{1.5}$ system. The optical properties of the resulting modified-ceria materials have been characterized in order to evaluate their potential abilities as inorganic UV absorbers. Diffuse reflectance analyses reveal a strong optical absorption between 390 and $400 \mathrm{~nm}$ for all substituted compositions and the spectral selectivities are estimated suitable for the targeted application. Additionally, Time Resolved Microwave Conductivity (TRMC) and phenol photodegradation analyses do not indicate any photocalatytic activity for these compositions. Aqueous colloidal suspensions of the $\mathrm{Ce}_{0.7} \mathrm{Y}_{0.3} \mathrm{O}_{1.85} \mathrm{UV}$ absorber have been carried out.
\end{abstract}




\section{Introduction}

The $\mathrm{CeO}_{2}-\mathrm{YO}_{1.5}\left(\mathrm{Y}_{2} \mathrm{O}_{3}\right)$ system has been widely described in literature [1-3]. Several properties are of interest such as the ionic conduction for which applications are developed in fuel cells (SOFCs). These oxides are excellent candidates to compete with yttrium-stabilized zirconia (YSZ) due to their higher ionic conductivity and their lower working temperatures.

As yttrium oxide absorbs widely in the UV part of the spectrum, the Y/Ce substitution is expected to shift efficiently the absorption edge of ceria towards shorter wavelengths, the latter usually being slightly located in the visible. Previous work on the fluorite-type solid solution $\mathrm{CeO}_{2}-\mathrm{Y}_{6} \mathrm{WO}_{12}$ has already shown the efficiency of modified-ceria for UV absorber applications [4]. Here, we are interested in taking advantage of a chemically simpler system in order to investigate and compare the synthesis of powders in the $\mathrm{CeO}_{2}-\mathrm{Y}_{2} \mathrm{O}_{3}$ solid solution using various synthetic approaches. The optical properties of these modified-ceria based materials were characterized in order to evaluate their potential abilities as inorganic UV absorbers. To date, zinc and titanium oxides are the main compounds used for such applications. However, they present two major drawbacks: (i) - they both manifest high photocatalytic activity under UV irradiation that can induce a photodegradation of the organic medium in which they are dispersed (varnish, paper, plastic ...); (ii) - they were originally optimized to be used as white pigments, in that way they exhibit high refractive indexes to diffuse visible light: titanium oxides - rutile: $n=2.7$, anatase: $n=2.5$. As a consequence, a whitening of the medium is generally observed which limits the use of such compounds in the case where a clear and colorless UV shield is needed (wood finishes, ...). In the last years, numerous papers have studied cerium oxide $\mathrm{CeO}_{2}$ as a possible alternative $(\mathrm{Eg}=3.2 \mathrm{eV}, \mathrm{n}=2.2)[1,2,5]$. Ceria manifests a lower photocatalytic activity than that of zinc and titanium oxides but it still has an important catalytic behavior for oxidation of organic compound limiting its commercial use [3]. Additionally, it also slightly absorbs in the visible range producing a yellowish coloring in the products, mostly undesired in specific applications. Recently, Yabe et al. have shown that the substitution of larger and/or less 
positively charged cations $\left(\mathrm{Ca}^{2+}, \mathrm{Sr}^{2+}, \mathrm{Ba}^{2+}, \mathrm{Mg}^{2+}, \mathrm{Zn}^{2+}\right)$ for $\mathrm{Ce}^{4+}$ can bring a suitable solution to the drawbacks of ceria [6]. Similar results have been described for the $\mathrm{CeO}_{2}-\mathrm{Y}_{6} \mathrm{WO}_{12}$ system [4].

A large part of this work focuses on the preparation and the characterization of powders absorbing exactly at $400 \mathrm{~nm}$, i.e. the UV/Visible transition. In order to finalize our approach in the synthesis of new efficient and emergent inorganic UV absorbers compatible with an industrial aqueous formulation, for instance an acrylic varnish for wood, we have developped several synthetic approaches in order to study the granulometry of the resulting powders, with the purpose of preparing UV absorber-containing suspensions.

\section{Experimental}

Oxide syntheses. The amorphous citrate route, i.e. a complexation/calcination method, was first involved to synthesize several compositions within the $\mathrm{CeO}_{2}-\mathrm{Y}_{2} \mathrm{O}_{3}$ system to evaluate their optical properties. In order to characterize the influence of the powder morphology on the optical properties, the most efficient stoichiometry was then isolated and its synthesis reinvestigated using different synthetic processes in addition to the citrate route: another complexation/calcination method (glycine nitrate route), a homogeneous coprecitation method and finally a colloidal approach for the preparation of a stable aqueous suspension.

Amorphous citrate route. It is not, strictly speaking, a classic sol-gel process in the usual sense that the gel is not formed by a metal-oxygen-metal network, but rather from calcination of metal-organic complexes, thus producing ultra fine reactive powders with an excellent chemical homogeneity [7]. Five compositions were investigated in the system (1-x) $\mathrm{CeO}_{2}-\mathrm{x} / 2 \mathrm{Y}_{2} \mathrm{O}_{3}$ with $\mathrm{x}=0,0.3,0.375,0.425$ and 0.5. Yttrium nitrate $\left(\mathrm{Y}\left(\mathrm{NO}_{3}\right)_{3}, 6 \mathrm{H}_{2} \mathrm{O} 99.99 \%\right.$, Alfa Aesar) and cerium nitrate $\left(\mathrm{Ce}\left(\mathrm{NO}_{3}\right)_{3}, 6 \mathrm{H}_{2} \mathrm{O}\right.$, Aldrich) were used as starting materials and dissolved in distilled water. Citric acid $\left(\mathrm{C}_{6} \mathrm{H}_{8} \mathrm{O}_{7}, \mathrm{Merck}\right.$, > 99\%) dissolved in a minimum amount of water was added to the solution in the proportion of one mole per cation valence, the addition being followed by a $30 \mathrm{~min}$ stirring step at $120{ }^{\circ} \mathrm{C}$. Since the complexation of cations by citric acid is improved at $\mathrm{pH} \geq 7$, the solution was neutralized by an 
ammonia solution (25\%, Merck) [8]. With increasing the $\mathrm{pH}$, the color of the solution changed from colorless to yellow indicating the oxidation of the $\mathrm{Ce}^{3+}$ ions to $\mathrm{Ce}^{4+}$ [9]. Then, the solution was stirred at $150{ }^{\circ} \mathrm{C}$ for $15 \mathrm{~min}$ to promote chelate formation. The liquid was progressively heated to $250{ }^{\circ} \mathrm{C}$, leading after $15 \mathrm{~h}$ to an expanded black solid residue. This product was finally ground and calcined a few hours at different temperatures 500,900 and $1000{ }^{\circ} \mathrm{C}$ in an alumina crucible in order to perform structural and optical characterizations.

Glycine nitrate route. This method evidences a selfcombustion reaction between nitrate-type precursors and glycine $\left(\mathrm{NH}_{2} \mathrm{CH}_{2} \mathrm{CO}_{2} \mathrm{H}\right)$ [10,11]. Glycine has a complexing role to enhance the solubility of precursors and to avoid any precipitation. This organic molecule offers two specific functions: - an amine function that complexes preferentially small size cations, as transition metals and small rare earth elements and - a carboxylic function for larger size elements among alkali, alkaline earth or lanthanide elements. It also plays the role of the fuel in the oxidation reaction by nitrate anions. Once cerium and yttrium nitrates are dissolved in water, glycine is added to the mixture under stirring. The optimized ratio was calculated to $5 \mathrm{n} / 9$ moles of glycine for one mole of cation, $\mathrm{n}$ represents the valence of the cation, in order to reach the maximum flame temperature. The temperature of the hot plate is raised at $200{ }^{\circ} \mathrm{C}$ until complete evaporation occurs. Then, a spontaneous combustion characterized by a high temperature flame produces the expected oxide.

Homogeneous coprecipitation method. The major interest of this synthetic approach is the controlled in-situ release of the precipitating agent from an organic compound into the solution [12,13]. Thus, hexamethylenetetramine (or HMT $-\mathrm{C}_{6} \mathrm{H}_{12} \mathrm{~N}_{4}$ ) can be slowly hydrolyzed into ammonia and formaldehyde. The yttrium and cerium solution $(0.075 \mathrm{M}, 300 \mathrm{~mL})$ is prepared by dissolution in distilled water of the desired ratios of the corresponding nitrates. Then, the HMT solution (1 M, 300 $\mathrm{mL}$ ) obtained by dissolution of the amine in water is added to the rare earths solution. The mixture is stirred for several hours until a fine precipitate forms. The latter is separated by centrifugation and 
washed several times to remove any trace of ammonia and organic residues. A moderate heating of the solution may help to start the nucleation/growth process.

Colloidal approach. The starting solution $\left(\left[\mathrm{Ce}_{0.7} \mathrm{Y}_{0.3} \mathrm{O}_{1.85}\right]=0.125 \mathrm{M}\right)$ was prepared from cerium nitrate (Rhodia, $\left[\mathrm{CeO}_{2}\right]=496 \mathrm{~g} / \mathrm{L}$ ) and yttrium nitrate (Rhodia, $\left[\mathrm{Y}_{2} \mathrm{O}_{3}\right]=382 \mathrm{~g} / \mathrm{L}$ ) solutions following the experimental protocol described elsewhere [14]. Ammonia was rapidly added to the solution and the obtained precipitate is then washed and centrifuged. A small amount of diluted nitric acid $(\sim 5 \%)$ was added to the precipitate as a peptizing agent and the resultant suspension was sonicated, centrifuged and the fine pale yellow resulting product was finally dried with acetone. The as-prepared powder was then dispersed into distilled water to form a series of solutions with selected concentrations from 0.4 to 3.6 g. $\mathrm{L}^{-1}$.

X-ray diffraction. XRD powder patterns were recorded using a Philips PW3710 diffractometer operating with $\mathrm{Cu} \mathrm{K} \mathrm{K}_{\alpha}$ radiation $(\lambda=1.5418 \AA)$. X'PERT softwares -Data Collector and Graphics and Identify- were used, respectively, for recording, analysis, and phase matching of the patterns. The lattice parameters were refined using Dicvol04 [15].

Specific surface area. A flowsorb II 2300 Micromeritics apparatus was used to determine the specific surface area of the powders by the single point method. Before measurement, the samples were outgassed under $\mathrm{He} / \mathrm{N}_{2}$ flow between 100 and $200{ }^{\circ} \mathrm{C}$ for $30 \mathrm{~min}$.

Granulometry. Particles size measurements of the powder samples were carried out with a BeckmanCoulter LS 230 laser granulometer in the $0.4-2000 \mu \mathrm{m}$ range. The nanosize range was determined for the colloidal suspensions using a Zetasizer Nano system from Malvern Instruments.

SEM. Powder morphology and particles size were checked using a JEOL JSM 6400 scanning electron microscope.

UV-Vis spectrophotometry. Diffuse reflectance spectra were collected using a Varian Cary 100 Scan spectrometer equipped with the Varian WinUV software and the integrating sphere Labsphere (DRC- 
CA-30I). Prior to measurements, the absolute reflectance of the samples was calibrated with a certified "spectralon" standard (Labsphere Cie). Experimental data were collected within the 250-800 nm range with $1 \mathrm{~nm}$ step and $0.5 \mathrm{~s}$ integration time. The position of the absorption edge was determined graphically at the inflexion point of the curve and the value of the optical gap using the theory of Kubelka-Munk [16]. Transmission spectra were performed using a Cary 5 spectrometer.

Refractive indexes. An estimation of the refractive index with an error of 5-10\% is possible using the Gladstone-Dale formula: $\mathrm{n}=1+\rho \Sigma \mathrm{m}_{\mathrm{i}} \mathrm{a}_{\mathrm{i}}$ where $\rho$ is the density of the compound $\mathrm{A}^{\mathrm{a}+}{ }_{\mathrm{x}} \mathrm{B}^{\mathrm{b}+}{ }_{\mathrm{y}} \mathrm{O}_{\mathrm{z}}, \mathrm{m}_{\mathrm{i}}$ is the weight fraction and $a_{i}$ is the refraction coefficient of the binary oxides $A^{a+} O \frac{a}{2}$ and $B^{b+} O \frac{b}{2}[17]$. The refractive index of a complex oxide can be considered as the sum of the contributions of each binary oxide that constitutes the compound. The $a_{i}$ coefficients were empirically determined for most of the binary oxides from their refractive indexes [18]. Jaffe has shown that very good results can be obtained for minerals with more or less complex compositions. For example, the estimated refractive index of calcium tungstate $\mathrm{CaWO}_{4}(1.921)$ is very close to the experimental value $\mathrm{n}=1.925$ [5].

Photocatalytic tests. The evaluation of the non-photocatalytic behavior of the substituted composition $\mathrm{Ce}_{0.5} \mathrm{Y}_{0.5} \mathrm{O}_{1.75 \mid} \quad 0.25$ was carried out in two steps. First, Time Resolved Microwave Conductivity (TRMC) was used for the investigation of the charge carriers lifetimes in the compound. In a second step, the photocatalytic activity of the material was further studied through the photodegradation of phenol. Basically, the powder is dispersed in an aqueous solution of phenol under vigorous stirring and oxygen bubbling. The suspension is then irradiated using a UV lamp and samples are withdrawn after various reaction times, filtrated and analyzed by UV-Visible absorption spectrometry to follow the concentration of phenol and the appearance of any photodegradation products. Principles and experimental set up of both analyses are fully described elsewhere $[6,19]$. 


\section{Results and Discussion}

Unlike in the $\mathrm{Ce}_{1-\mathrm{x}} \mathrm{Y}_{6 \mathrm{x} / 7} \mathrm{~W}_{\mathrm{x} / 7} \mathrm{O}_{2-2 \mathrm{x} / 7} \square_{2 \times / 7}$ system where a complete fluorite-type solid solution has been evidenced [4], Gabbitas et al. report the presence of two domains of compositions in the $\mathrm{Ce}_{1-}$ ${ }_{x} Y_{x} \mathrm{O}_{2-x / 2} \square_{x / 2}$ system [1]. As illustrated in Figure 1, for $\mathrm{x}<0.50$, the corresponding structures are of the fluorite-type; when $\mathrm{x}>0.73$, a structure close to $\mathrm{Y}_{2} \mathrm{O}_{3}$ is observed. This compound is characterized by a bixbiyte-type structure, namely of the C-type, related to a fluorite, for which the unit cell parameter has been doubled ( $\left.\mathrm{a}_{\mathrm{C}-\mathrm{Type}}=2 * \mathrm{a}_{\text {Fluorite }}\right)$. The intermediate range of compositions $(0.50<\mathrm{x}<0.73)$ corresponds to a non-miscibility region where the two structure-types coexist. However, the limit of the fluorite-type domain remains uncertain as another study attributes it only to a value of $x=0.35$ [3]. The main difference between the both structures lies in an oxygen/vacancies ordering.

\subsection{Amorphous citrate route}

Using the citrate route, five compositions - i.e. $\mathrm{x}=0,0.3,0.375,0.425$ and 0.5 - have been synthesized starting from cerium $\mathrm{Ce}\left(\mathrm{NO}_{3}\right)_{3}, 6 \mathrm{H}_{2} \mathrm{O}$ and yttrium $\mathrm{Y}\left(\mathrm{NO}_{3}\right)_{3}, 6 \mathrm{H}_{2} \mathrm{O}$ nitrates in order to check the extent of the fluorite-type solid solution domain above-described. Experimental data, synthesis conditions and characteristic values from diffuse reflectance spectroscopy are given in Table 1. XRD patterns of the samples calcined at $1000{ }^{\circ} \mathrm{C}$ (Fig. 2) show that only the compositions for $\mathrm{x} \leq 0.3$ appear to be a pure fluorite-type phase without any C-type byproduct. These results confirm that the fluoritetype domain should be limited to the values of $\mathrm{x}<0.35$ and not 0.5 , as suggested by Gabbitas et al.

The evolution of the absorption profile in $\mathrm{Ce}_{0.7} \mathrm{Y}_{0.3} \mathrm{O}_{1.85} \square_{0.15}$ versus temperature is quite similar for all the studied compositions. As described previously for $\mathrm{CeO}_{2}-\mathrm{Y}_{6} \mathrm{WO}_{12}$ [4], when the sample is heated at $500{ }^{\circ} \mathrm{C}$, the absorption edge is relatively large $(\Delta \lambda=44 \mathrm{~nm})$ and beyond $400 \mathrm{~nm}(\lambda=415 \mathrm{~nm})$ that is in agreement with the yellow color of the powder. After a heating step at $900{ }^{\circ} \mathrm{C}$, the spectral selectivity increases $(\Delta \lambda=33 \mathrm{~nm})$ and the absorption edge shifts towards smaller wavelengths $(\lambda=393$ 
$\mathrm{nm})$ as the powder turns white. A subsequent calcination at higher temperature $\left(1000{ }^{\circ} \mathrm{C}\right)$ does not cause any modification in the position of the edge, but still leads to a steeper edge $(\Delta \lambda=29 \mathrm{~nm})$.

Diffuse reflectance spectra of the samples heated at $1000{ }^{\circ} \mathrm{C}$ are given in Fig. 3. All the substituted compositions exhibit a similar behavior with an absorption edge located around $390 \mathrm{~nm}$ and a spectral selectivity close to $30 \mathrm{~nm}$ as gathered in Table 1 . In contrast to the pale yellow color of the non-substituted ceria, they do not manifest any absorption in the visible range of the spectrum. Therefore, all these compositions are of interest as inorganic UV absorbers.

\subsection{Influence of the synthesis method}

In order to determine the influence of the preparation method on the powder morphology and the optical properties, we have focused our attention on the composition $\mathrm{Ce}_{0.7} \mathrm{Y}_{0.3} \mathrm{O}_{1.85} \square_{0.15}$, i.e. $\mathrm{x}=0.3$, using three different processes: the amorphous citrate route starting from commercial nitrates $\mathrm{R}\left(\mathrm{NO}_{3}\right)_{3}, 6 \mathrm{H}_{2} \mathrm{O}(\mathrm{R}=\mathrm{Y}, \mathrm{Ce})$; the glycine nitrate method using cerium and yttrium nitrate solutions; and a homogeneous coprecipitation route using HMT and the commercial nitrate precursors. Powders resulting from the different processes have been analyzed by laser granulometry, SEM and BET analyses.

Amorphous citrate route. Considering the sample prepared at $500{ }^{\circ} \mathrm{C}$, granulometry curves denote the presence of a large number of particles with size between 1 and $5 \mu \mathrm{m}$ as well as larger grains up to 120 $\mu \mathrm{m}$ (Fig. 4). SEM pictures reveal compact aggregates composed of finer particles (diameter $<1 \mu \mathrm{m})$ as shown on Fig. 5a. The structure of the powder, which aspect reproduces the texture of the expanded solid observed during the synthesis, leads to a high specific surface area of $74 \mathrm{~m}^{2} \cdot \mathrm{g}^{-1}$. The calcination step at $900{ }^{\circ} \mathrm{C}$ does not affect considerably the granulometry (Fig. 6). However, SEM pictures (Fig. 5b) reveal a densification of the aggregates that results in a dramatic decrease in the specific surface area $\left(\mathrm{S}_{\mathrm{g}}=9 \mathrm{~m}^{2} \cdot \mathrm{g}^{-1}\right)$ 
Glycine-nitrate route. The granulometric analyses carried out on the samples prepared at $500{ }^{\circ} \mathrm{C}$ and $900{ }^{\circ} \mathrm{C}$ indicate the presence of a large number of particles with sizes close to $500 \mathrm{~nm}$ as well as few larger ones (Fig. 4). For the latter, the maximum size decreases when the calcination temperature is raised from $500^{\circ} \mathrm{C}$ to $900^{\circ} \mathrm{C}$, i.e. $\emptyset_{\max }\left(500^{\circ} \mathrm{C}\right)=190 \mu \mathrm{m}$ and $\varnothing_{\max }\left(900^{\circ} \mathrm{C}\right)=130 \mu \mathrm{m}$. This result can be related to the densification of the aggregates with temperature, in agreement with the important decrease in the specific surface area from 44 to $8 \mathrm{~m}^{2} \cdot \mathrm{g}^{-1}$. The SEM pictures performed on the sample calcined at $900{ }^{\circ} \mathrm{C}$ display a singular appearance as shown in Fig. $5 \mathrm{c}$ and d. The open texture is likely a consequence of the synthesis method that involved a rapid and highly exothermic combustion reaction along with an important gaseous release. A highly magnified SEM image shows that the powder is made of aggregates of particles with sizes smaller than $10 \mathrm{~nm}$ (Fig 5d).

Homogeneous coprecipitation route (HMT). As displayed on figures 4 and 6, distribution curves corresponding to both the samples calcined at $500{ }^{\circ} \mathrm{C}$ and $900{ }^{\circ} \mathrm{C}$ confirm that most of the particles have a size smaller than $500 \mathrm{~nm}$. Figures 4 and 6 also indicate the presence of bigger particles, but the sizes remain below $100 \mu \mathrm{m}$, and the calcination temperature does not significantly change the granulometric distribution. Compared to the complexation-calcination processes, i.e. amorphous citrate and glycine nitrate routes, SEM analysis depicts a totally different behavior. Powders resulting from the HMT coprecipitation are made of agglomerates of very fine and non-dense spherical particles. The size of the elementary grain seems to be lower than $10 \mathrm{~nm}$ as pointed out on figure 5 e and $\mathrm{f}$. BET measurements indicate high specific surface areas, even after the high temperature treatment: $\mathrm{S}_{\mathrm{g}}\left(600{ }^{\circ} \mathrm{C}\right)$ $=110 \mathrm{~m}^{2} \cdot \mathrm{g}^{-1}, \mathrm{~S}_{\mathrm{g}}\left(900^{\circ} \mathrm{C}\right)=70 \mathrm{~m}^{2} \cdot \mathrm{g}^{-1}$.

XRD powder patterns of the samples synthesized by combustion routes, i.e. amorphous citrate and glycine nitrate routes, present a comparable profile. Calcinations at $500{ }^{\circ} \mathrm{C}$ produce poorly crystallized powders, but a fluorite structure-type can be distinguished yet. A further heating at $900{ }^{\circ} \mathrm{C}$ involves a crystallization of the products as noticed on the XRD patterns (Fig. 7). Table 2 summarizes 
the optical characteristics of all the prepared samples. Diffuse reflectance spectra of the powders heated at $900^{\circ} \mathrm{C}$ indicate minor shifts in the position of the absorption edge; however it remains in the range of 380-400 nm, without any incidence on the spectral selectivity (Fig 8). HMT coprecipitation method leads to totally different results. XRD patterns reveal very broad and weak diffraction peaks even after calcination of the sample at high temperature as shown on figure 7. Compared to the well crystallized product prepared by the citrate route at $900{ }^{\circ} \mathrm{C}$, the profile of the pattern lets suppose that the size of the diffracting crystallites is much smaller in that case. This experimental route gives the products a higher spectral deviation. This lower selectivity may be correlated to the general crystallization state of the sample, lower than that observed in the other synthetic approaches (Table 2).

The literature usually attributes refractive indexes close to 1.85 and 2.20 for yttrium and cerium oxides respectively. The refractive indexes for the substituted compositions have been estimated using the Gladstone-Dale relation and are gathered in Table 3. By comparison to the main marketed inorganic UV absorbers, in particular with $\mathrm{TiO}_{2}(\mathrm{n}=2.7$ for rutile and 2.5 for anatase), the refractive indexes calculated for the prepared samples in the $\mathrm{CeO}_{2}-\mathrm{Y}_{2} \mathrm{O}_{3}$ system are in the range 2.0-2.1 and let figure less whitening troubles considering the dispersion of the powders into a clear and colorless application medium.

\section{3 photodegradation of phenol}

The above results point out that the substituted compositions manifest a strong absorption for the UV light with an absorption edge located between 390 and $400 \mathrm{~nm}$, and that the expected refractive indexes are lower than that of ceria. In order to fully determine their potential as inorganic UV absorbers, their photocatalytic behavior needs to be characterized. If incorporated in a solid or liquid medium, the UV absorber should not react with its close environment from a photocatalytic viewpoint. We have chosen to evidence the non-photoactivity by studying the reaction between phenol, which derivatives are major components of woods and the absorber under UV light. 
TRMC and phenol photodegradation analyses were carried out on the $\mathrm{Ce}_{0.7} \mathrm{Y}_{0.3} \mathrm{O}_{1.85} \quad{ }_{0.15}$ composition which corresponds to the pure fluorite-type sample. TRMC results indicate that no charge carriers were created under UV irradiation. For comparison, when $\mathrm{TiO}_{2}$ is illuminated with UV light, the photon energy is high enough so that an electron of the valence band can move to a level of the conduction band. It results the formation of an electron/hole pair. If these charge carriers do not recombine in the bulk, they can migrate to the surface and be trapped by metallic or oxygen ions [20]. The trapped charge carriers react with $\mathrm{O}_{2}$ and $\mathrm{H}_{2} \mathrm{O}$ to form free radicals which are very oxidative species able to decompose any present organic compounds into $\mathrm{CO}_{2}$ and $\mathrm{H}_{2} \mathrm{O}$. The fact that no charge carriers were observed in the case of the phase $\mathrm{Ce}_{0.7} \mathrm{Y}_{0.3} \mathrm{O}_{1.85} \square_{0.15}$ lets suppose that this composition does not exhibit any photocatalytic activity. This result is confirmed by the phenol photodegradation test (Fig. 9). The absorption spectra of samples withdrawn after various reaction times do not reveal any degradation of the phenol. For information, the phenol which has an absorption band between 240 and $290 \mathrm{~nm}$ does not decompose by itself under UV illumination. But in the presence of a photocatalytic material such as $\mathrm{TiO}_{2}$, it decomposes into hydroquinone which absorbs between 250 and $310 \mathrm{~nm}$ and benzoquinone which strongly absorbs for $\lambda<260 \mathrm{~nm}$. Additionally the diminution in the phenol concentration results in a decrease in its absorption band [21]. As none of the quinones bands are observed in the case of the $\mathrm{Ce}_{0.7} \mathrm{Y}_{0.3} \mathrm{O}_{1.85} \quad 0.15$ composition, we have concluded that this material does not manifest any photocatalytic behavior although $\mathrm{CeO}_{2}$ is given to have some photocatalytic activity [6]. The progressive introduction of vacancies in the anionic network along with yttrium substitution can provide a possible explanation for this result. We assume that the anionic vacancies act like a trap for the charge carriers that can then quickly recombine. So they cannot reach the surface of the materials to induce the formation of free radicals, responsible for the decomposition of organics such as phenol.

\section{4 colloidal approach}


Combustion syntheses (citrate and glycine methods) are suitable for the preparation of multicationic and complex compositions, but unfortunately they do not allow an efficient control of the granulometry. The range of temperatures reached during the syntheses favors the formation of hard aggregates with relatively high dimensions (diameter $>100 \mu \mathrm{m}$ ). In the context of wood varnishes, this feature limits therefore the utility of such powders to realize homogeneous fine particles suspensions. The powders obtained via the homogeneous coprecipitation (HMT) present more interesting and advantageous characteristics to our study. The elementary grain size is evaluated to be close to $10 \mathrm{~nm}$. However, the formation of fine particles packs, probably due to electrostatic forces, indicates a trend for the grains to agglomerate. This point represents an inconvenient to produce a homogeneous dispersion of the particles and to avoid any sedimentation in solution. Alternatively, the use of peptizing agents is a priori conceivable. However, the preparation of a nanometric suspension following colloidal routes looks more realistic and appropriate to the use of such UV absorbers in solution, for example in the varnish market.

Dispersion of a fine powder of the $\mathrm{Ce}_{0.7} \mathrm{Y}_{0.3} \mathrm{O}_{1.85} \mathrm{UV}$ absorber in water has been carried out using an experimental procedure previously described [14]. The oxide suspension was first prepared as a mother solution with a concentration of 3.65 g.L.-1. Appropriate dilutions were then performed to lead to a range of concentrations down to 0.37 g.L.- Figure 10 represents the corresponding absorption curves obtained by transmission spectrometry. The blue shift of the absorption edge that is observed with dilution indicates that the UV-shielding behavior of the as-prepared oxide suspension is getting less efficient compared to the starting material. However for oxide concentration greater than 2 g.L $\mathrm{L}^{-1}$, the selective absorption of the UV light remains acceptable. Size distribution plots were similar to that presented in Fig. 10 with an average particle size ranging from 55 to $65 \mathrm{~nm}$ and a standard deviation of $30 \mathrm{~nm}$. The as-prepared suspensions were stable for at least 5 months without any noticeable 
sedimentation. Those basic and simple experiments reveal that such suspensions could be easily transposed to industrial acrylic varnishes and finishing.

\section{Conclusion}

We have shown the possibility to tune the absorption edge position of ceria by substituting yttrium for cerium atoms towards the UV/Vis transition $(400 \mathrm{~nm})$. All the studied compositions manifest a strong absorption in the 390-400 nm with estimated refractive indexes between 2.0 and 2.1 which are lower than those of $\mathrm{CeO}_{2}$ and $\mathrm{TiO}_{2}$. Moreover, negative photocatalytic tests with phenol allow to consent that these compositions are interesting as UV absorbers for the wood industry. Subsequent attempts to prepare fine suspensions of absorber in water appear to be promising to be developed in liquid media such as acrylic-based varnishes.

\section{Acknowledgment}

The French "Ministère de l'Economie et des Finances" supported financially the AUVIB program (novel UV Inorganic Absorbers to limit the photodegradation of wood - $\mathrm{n}^{\circ} 024906002$ ) belonging to the Réseau National Matériaux et Procédés (RNMP). www.reseau-materiaux.com.fr. The authors are gratefull to Rhodia Electronics and Catalysis (Aubervilliers, la Rochelle) for providing rareearth nitrate solutions during the above-mentioned program and to Dr. Stéphane Jobic and Stéphane Grolleau for the access to laser granulometry at the Institut des Matériaux Jean Rouxel in Nantes. 


\section{References}

1 N. Gabbitas, J. G. Thompson, R. L. Withers, A. D. Rae, J. Solid State Chem. 115 (1995) 23-26.

2 J.-G. Li, T. Ikegami, Y. Wang, T. Mori, J. Solid State Chem.168 (2002) 52-59.

3 J. Van herle, T. Horita, T. Kawada, N. Sakai, H. Yokokawa, M. Dokiya, J. Am. Ceram. Soc., 80 (1997) 933-940.

4 F.Cheviré, F. Muñoz, C.F. Baker, F. Tessier, O. larcher, S. Boujday, C. Colbeau-Justin and R. Marchand, J. Solid State Chem., 179 (2006) 3184-3190.

5 H. W. Jaffe, Amer. Mineral., 41 (1956) 757-777.

6 R. Li, S. Yabe, M. Yamashita, S. Momose, S. Yoshida, S. Yin, T. Sato, Mater. Chem. Phys., 75 (2002) 39-44.

7 F. Tessier, R. Marchand, J. Solid State Chem., 171 (2003) 143-151.

8 A. Douy, P. Odier, Mater. Res. Bull., 24 (1989) 1119-1126.

9 K. Binnemans, C. Görller-Walrand, Chem. Phys. Lett., 235 (1995) 163-174

10 L.A. Chick, L.R. Pederson, G.D. Maupin, J.L. Bate, L.E. Thomas, G.J. Exarhos, Mater. Lett., 10 (1990) 6-12.

11 F. Cheviré, Thesis n 3061, Université de Rennes 1, France, 2001.

12 P.L. Chen, I.W. Chen, J. Am. Ceram. Soc., 76 (1933) 1577-1583.

13 J. Markmann, A. Tschöpe, R. Birringer, Acta Mater., 20 (2002) 1433-1440.

14 A.S. Deshpande, N. Pinna, P. Beato, M. Antonietti and M. Niederberger, Chem. Mater., 16 (2004) 2599-2604.

15 A. Boultif, D. Louer, J. Appl. Cryst., 37 (2004) 724-731.

16 D. Kubelka, L. Munk, Z. Teck. Physik., 12 (1931) 593-601.

17 R. Newnham, Structure-Property relations, Springer 1994.

18 J. A. Mandarino, Can. Miner., 19 (1981) 441-450.

19 C. A. Emilio, M. I. Litter, M. Kunst, M. Bouchard, C. Colbeau-Justin Langmuir 22(8) (2006) 3606-3613.

20 S. Boujday, F. Wünsch, P. Portes, J. F. Bocquet, C. Colbeau-Justin, Sol. Energy Mater. Sol. Cells, 85 (2004) 421-433.

21 L. Znaidi, R. Séraphimova, J. F. Bocquet, C. Colbeau-Justin, C. Pommier, Mater. Res. Bull., 36 (2001) 811-825. 


\section{Figures and tables captions}

Figure 1: Solid solution domains in the $\mathrm{Ce}_{1-\mathrm{x}} \mathrm{Y}_{\mathrm{x}} \mathrm{O}_{2-\mathrm{x} / 2} \square_{\mathrm{x} / 2}$ system.

Figure 2: Powder diffraction patterns of the samples calcined at $1000{ }^{\circ} \mathrm{C}$. Arrows indicate the X-ray lines of the C-type phase.

Figure 3: Diffuse reflectance spectra of calcined samples at $1000{ }^{\circ} \mathrm{C}$.

Figure 4: Differential number and volume plots versus particle size of the powders heated at $500{ }^{\circ} \mathrm{C}$ $\left(600{ }^{\circ} \mathrm{C}\right.$ for HMT reaction).

Figure 5: SEM pictures of the powders calcined at $500{ }^{\circ} \mathrm{C}(\mathrm{a})$ and $900{ }^{\circ} \mathrm{C}(\mathrm{b})$, of the powder prepared by the glycine route and calcinated at $900{ }^{\circ} \mathrm{C}$ (c) and (d), and of the powders prepared by coprecipitation (HMT) and calcinated at $600{ }^{\circ} \mathrm{C}(\mathrm{e})$ and $900{ }^{\circ} \mathrm{C}(\mathrm{f})$

Figure 6: Differential number and volume plots versus particle size of the powders heated at $900{ }^{\circ} \mathrm{C}$.

Figure 7: Comparison between the XRD profiles of samples prepared by citrate and coprecipitation routes.

Figure 8: Diffuse reflectance spectra of the three samples heated at $900^{\circ} \mathrm{C}$.

Figure 9: Phenol photodegradation test with the $\mathrm{Ce}_{0.7} \mathrm{Y}_{0.3} \mathrm{O}_{1.85} \square_{0.15}$ composition.

Figure 10: Absorption spectra (transmission) of a series of diluted $\mathrm{Ce}_{0.7} \mathrm{Y}_{0.3} \mathrm{O}_{1.85}$ solutions and particles size distribution in the $\mathrm{Ce}_{0.7} \mathrm{Y}_{0.3} \mathrm{O}_{1.85}$ solution $\left(0.37 \mathrm{~g}^{-1} \cdot \mathrm{L}^{-1}\right)$.

Table 1: Characteristic values from the diffuse reflectance spectra for the samples prepared by the citrate route.

Table 2: Characteristic values of diffuse reflectance spectra for the compositions $\mathrm{x}=0,3$ prepared according to the mentioned methods.

Table 3: Refractive indexes calculated using the Gladstone-Dale formula in the $\mathrm{CeO}_{2}-\mathrm{YO}_{1,5} \square 0,5$ $\left(\mathrm{Y}_{2} \mathrm{O}_{3}\right)$ system. 
Figure 1

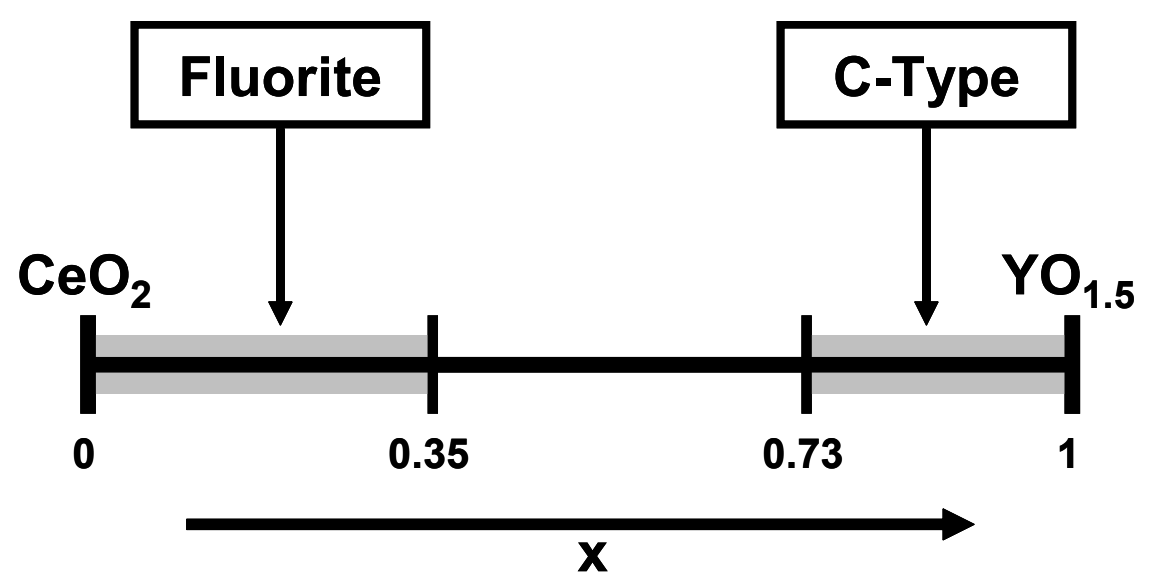


Figure 2

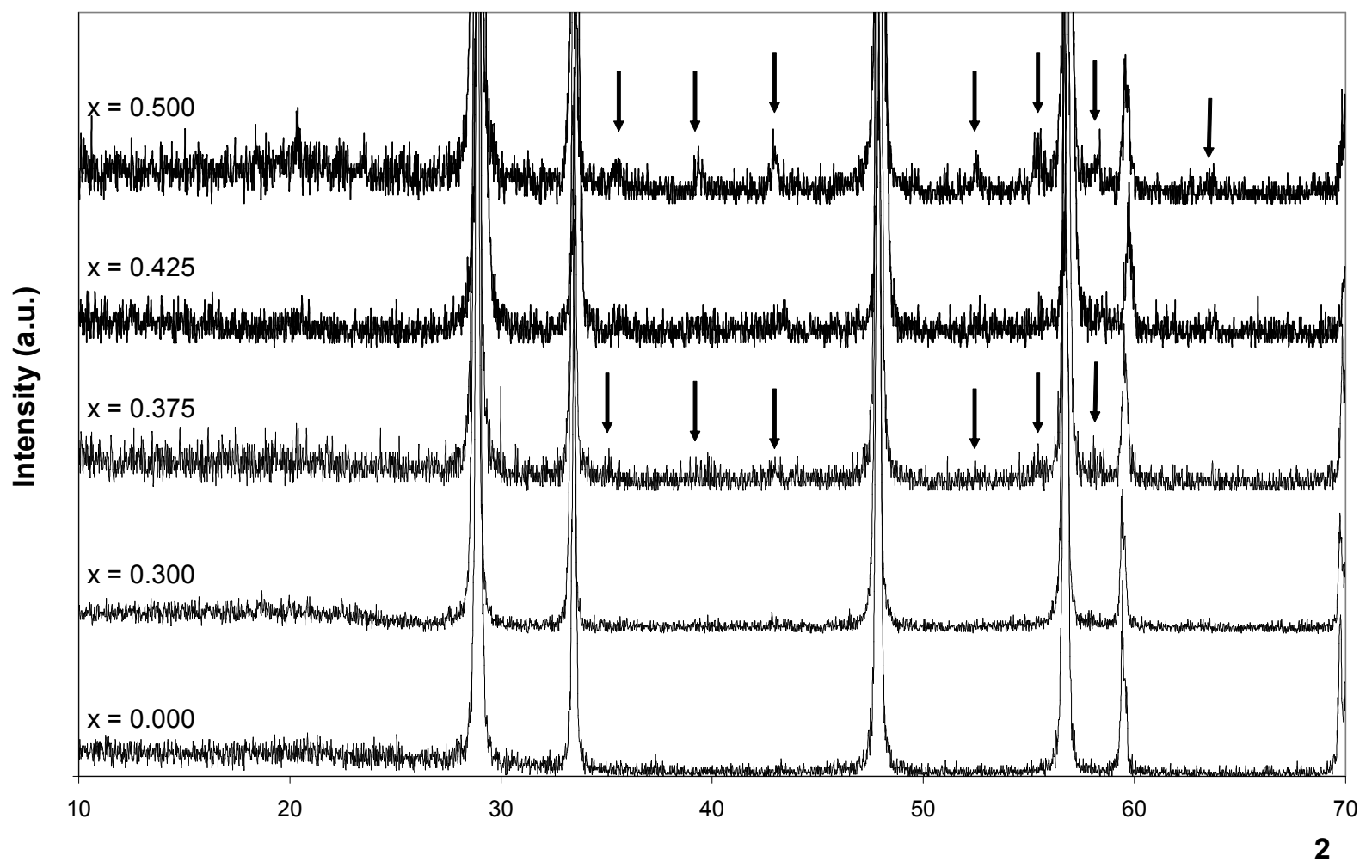


Figure 3

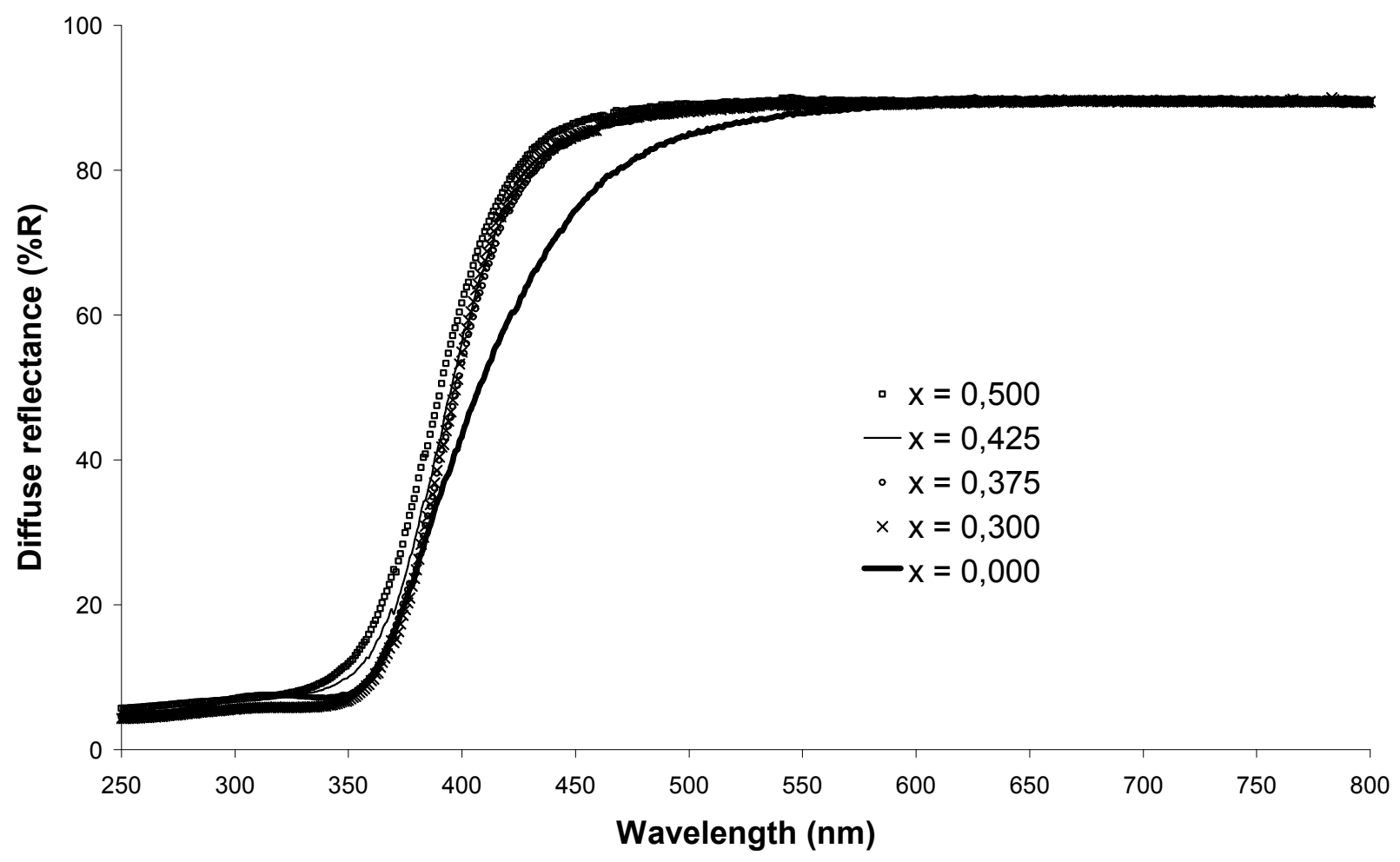


Figure 4

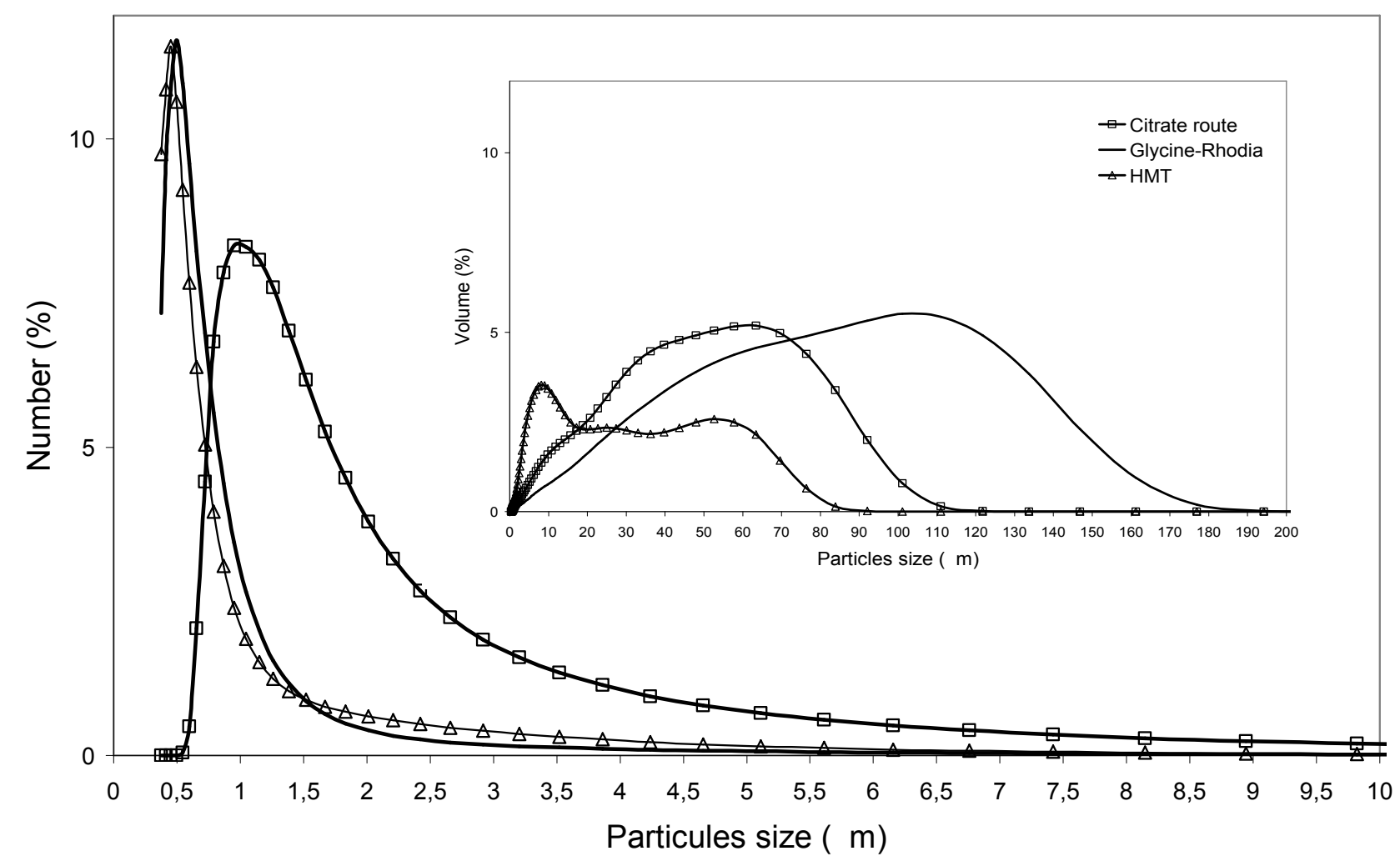


Figure 5
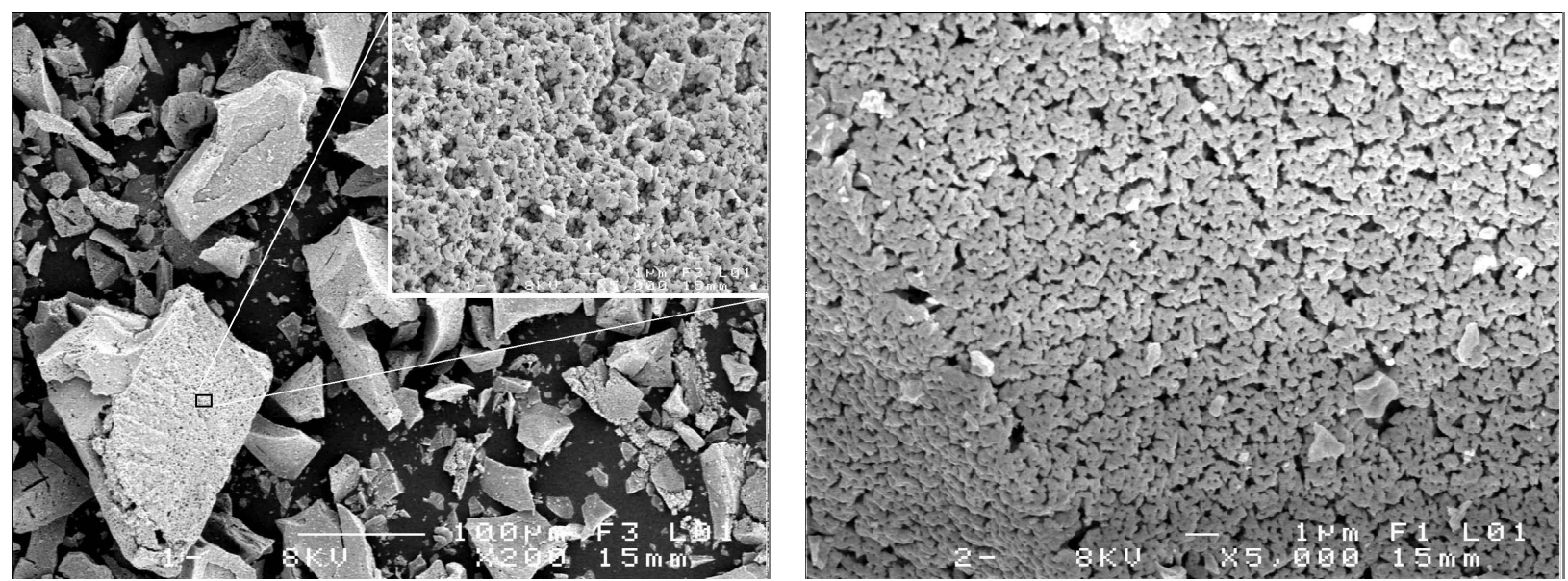

(a)

$100 \mu \mathrm{m}$

(b)

$-1 \mu \mathrm{m}$
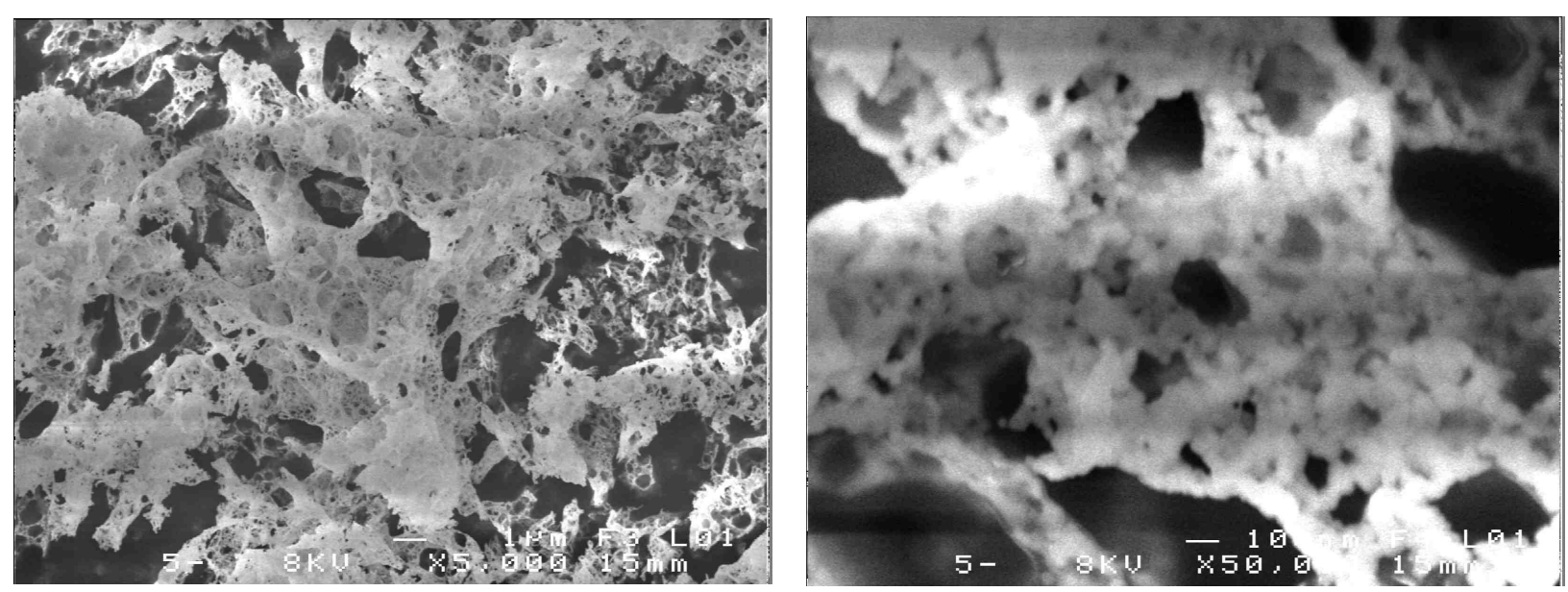

(c)

$-1 \mu \mathrm{m}$

(d)

$-10 \mathrm{~nm}$
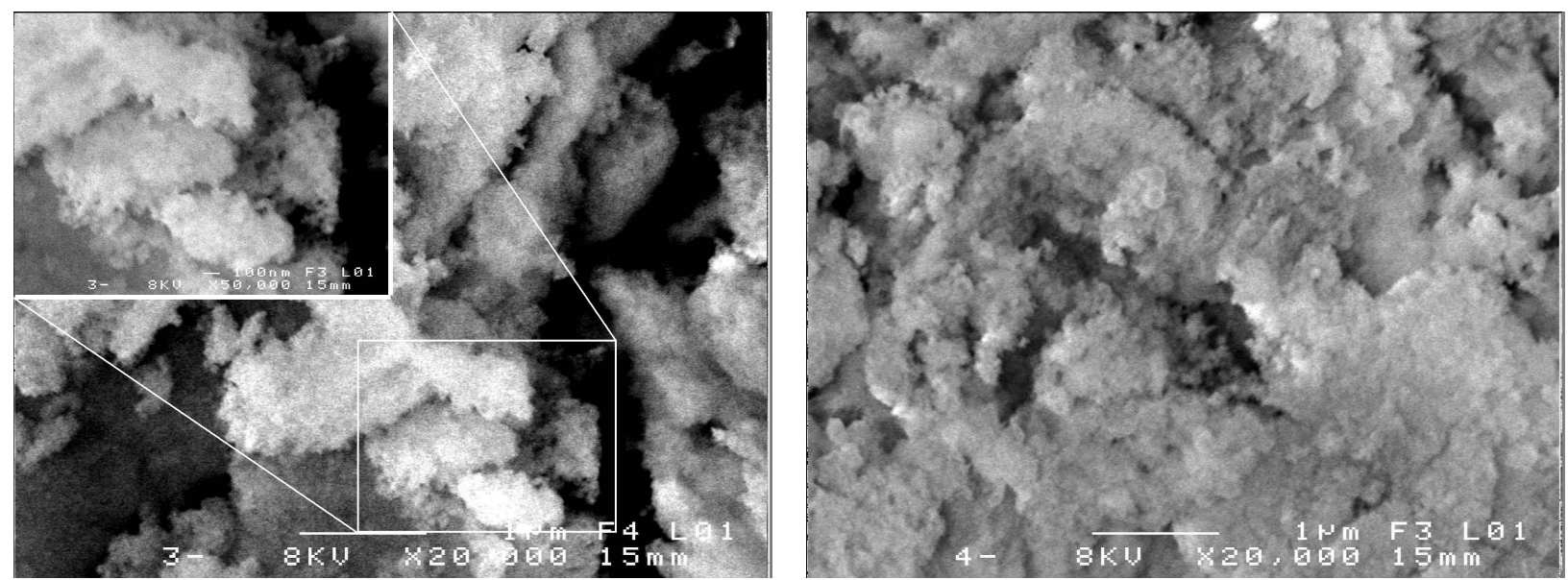

(e)

$1 \mu \mathrm{m}$

(f)

$1 \mu \mathrm{m}$ 
Figure 6

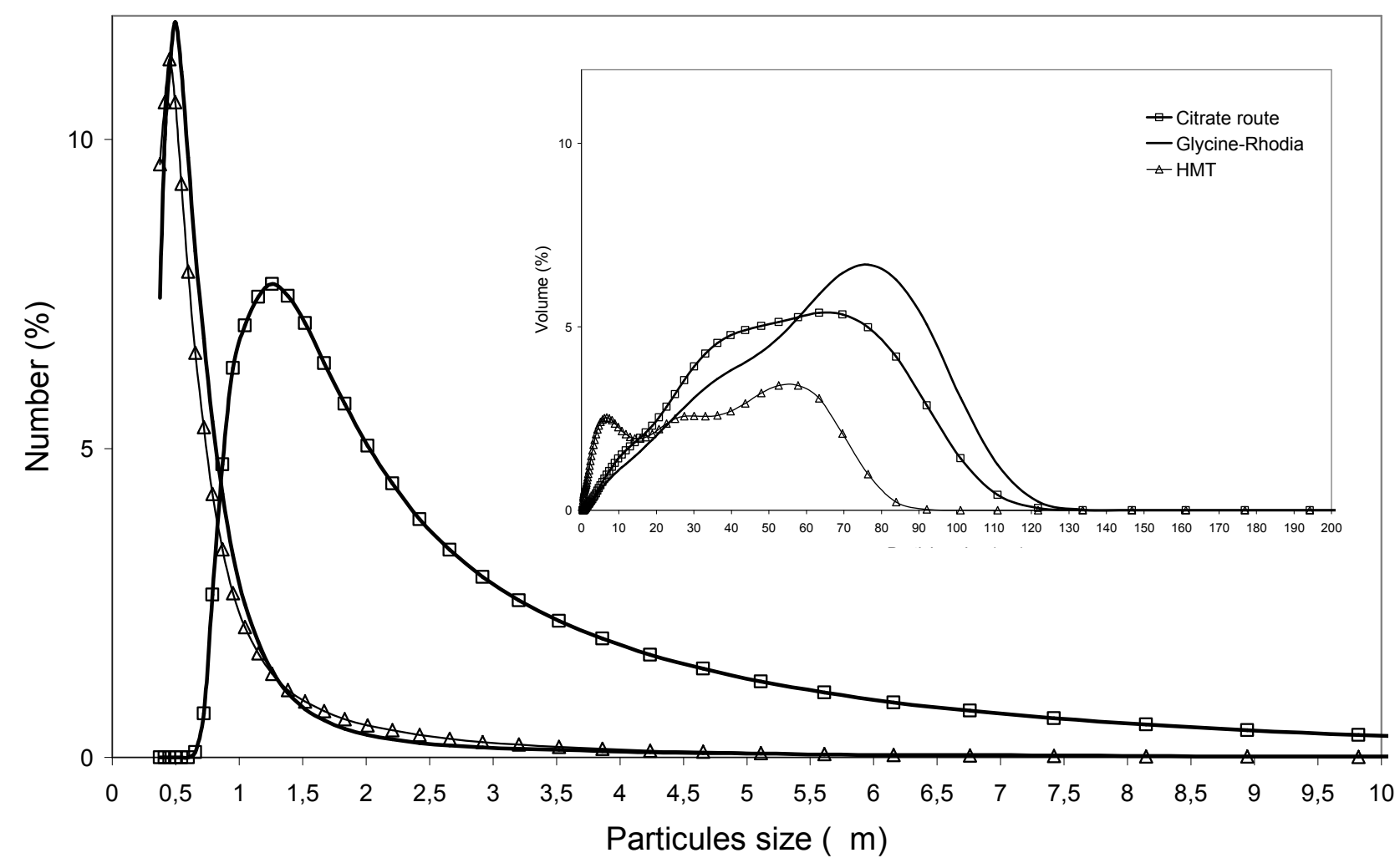


Figure 7

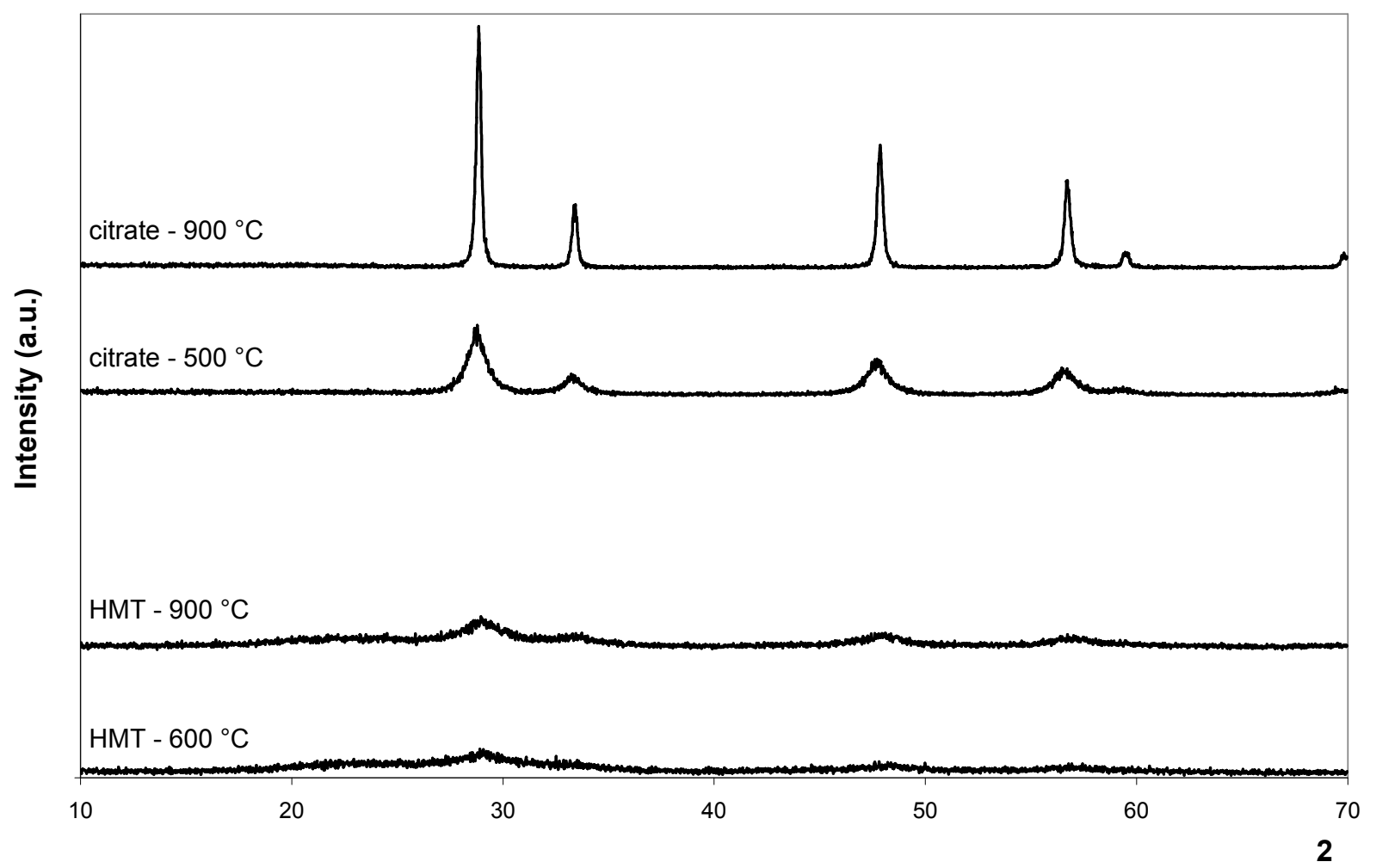


Figure 8

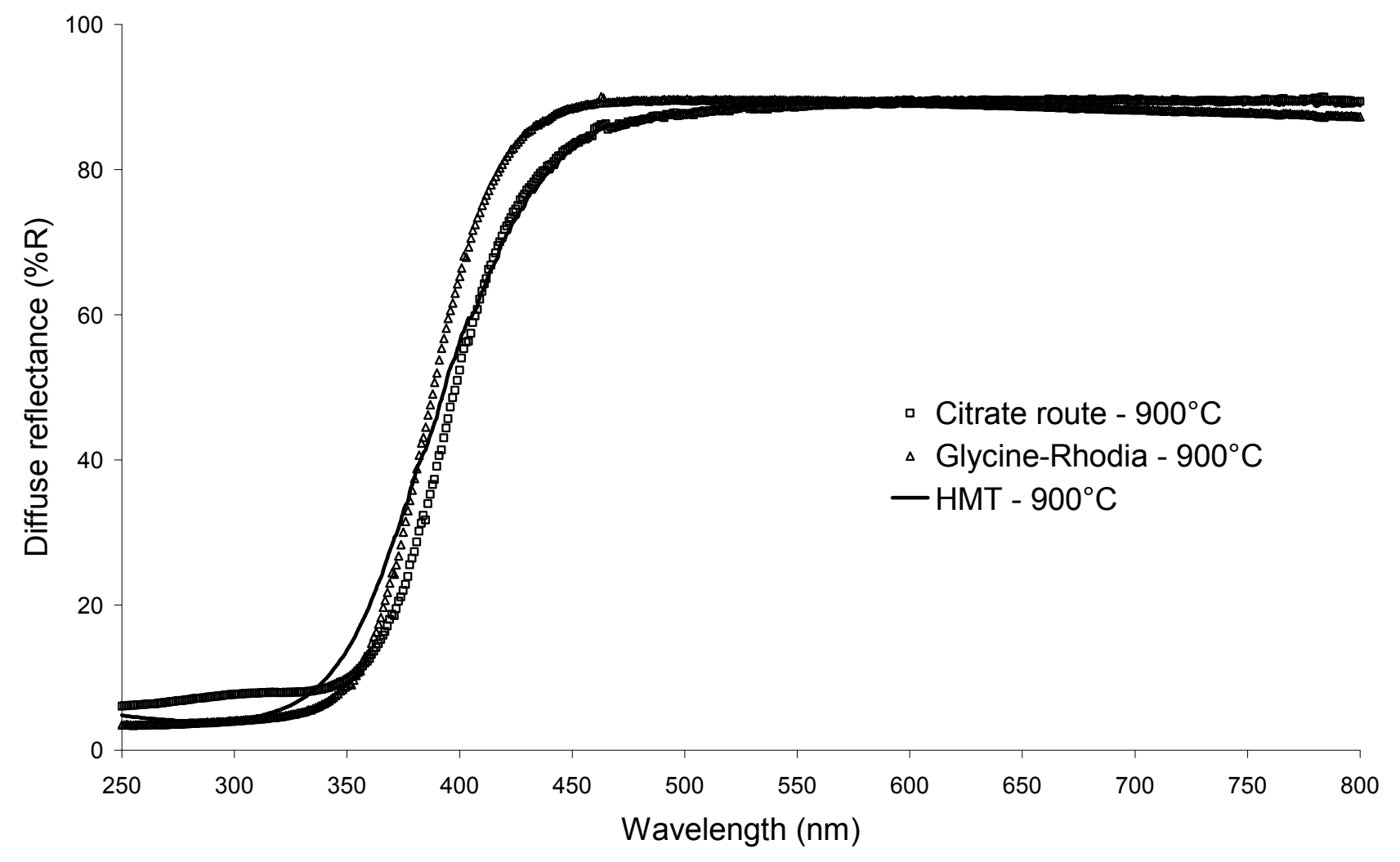


Figure 9

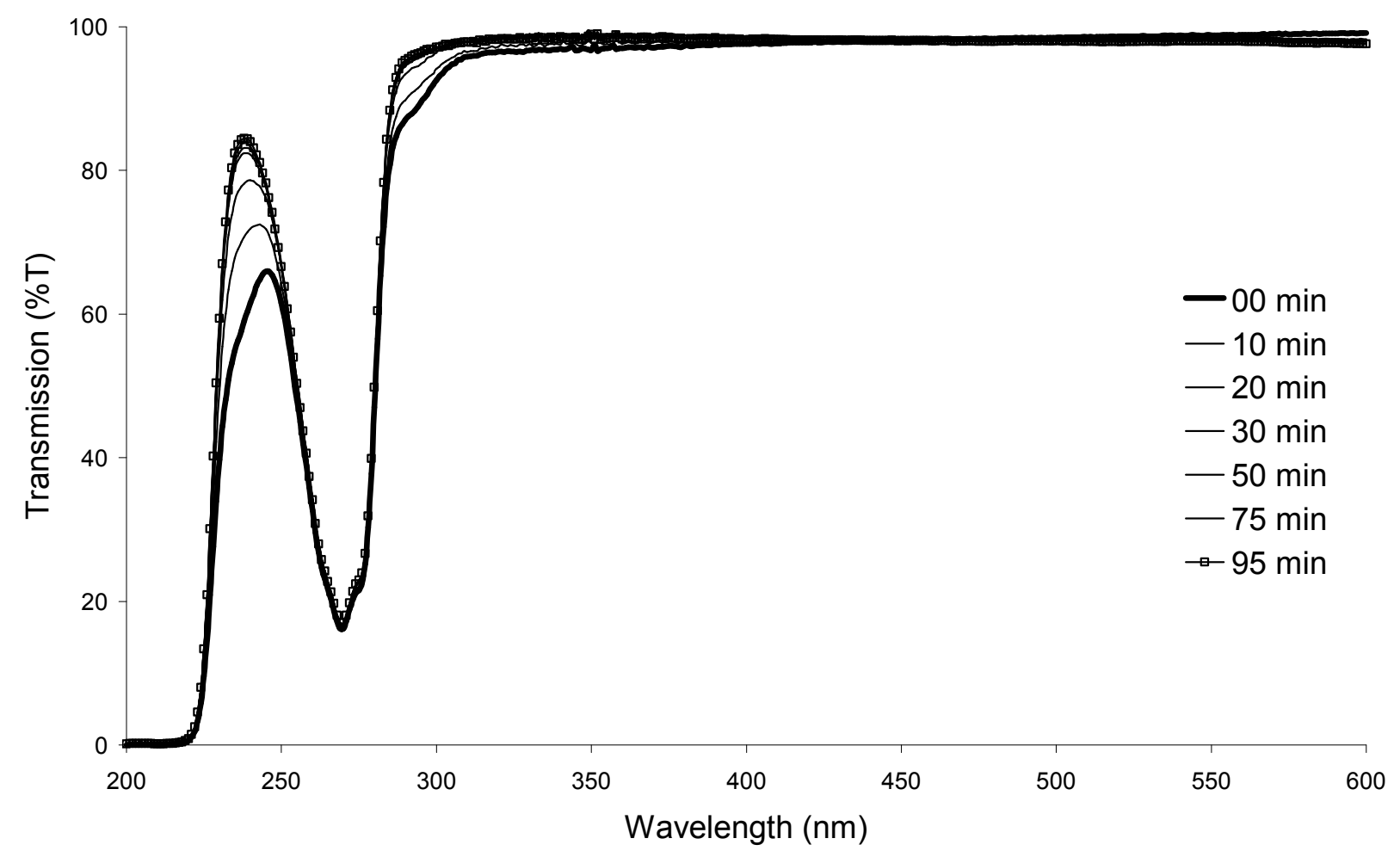


Figure 10

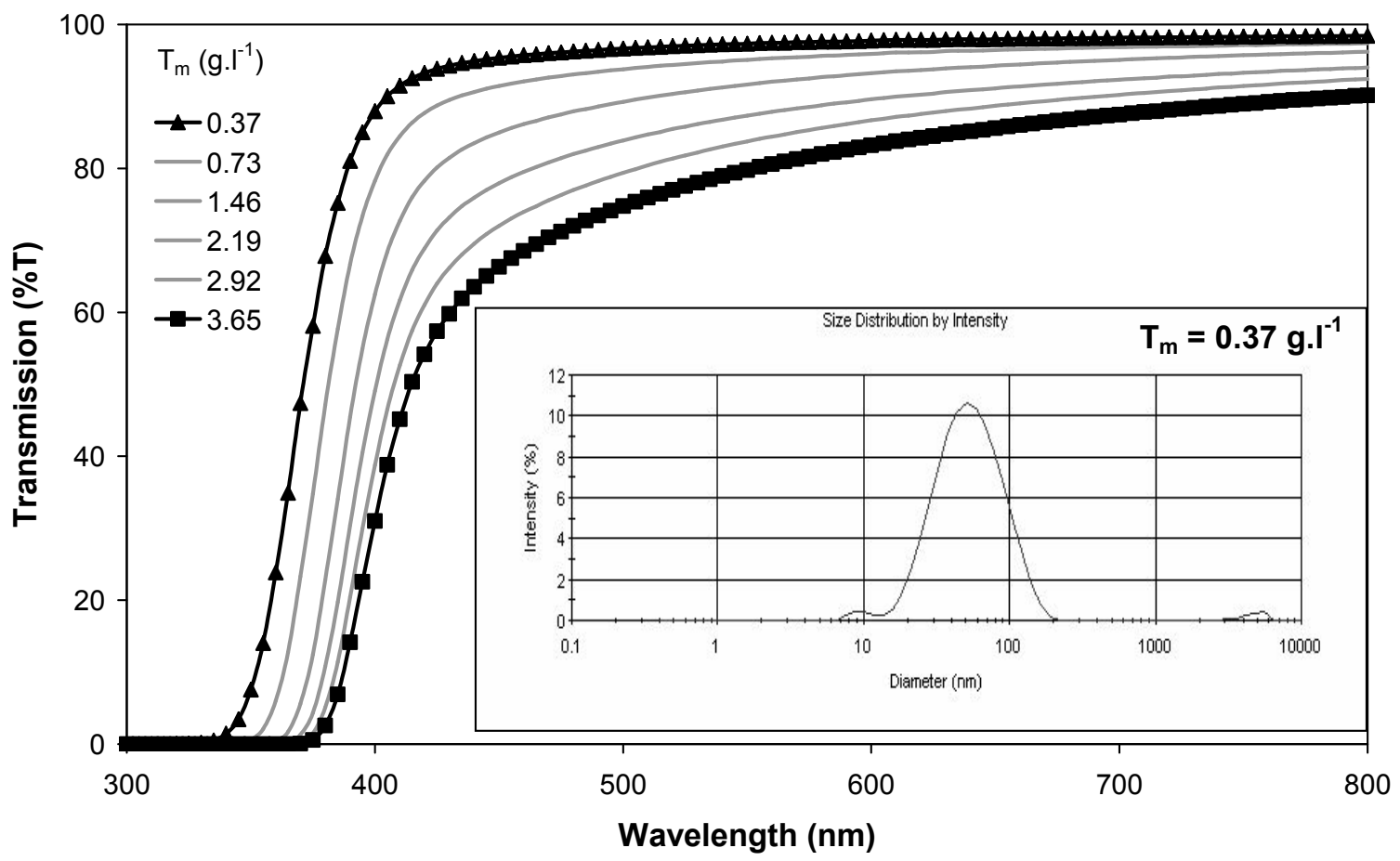


Table 1

\begin{tabular}{ccccc}
\hline $\mathbf{x}$ & $\begin{array}{c}\text { Calcination } \\
\text { temperature }\left({ }^{\circ} \mathrm{C}\right)\end{array}$ & $\lambda \pm \Delta \lambda(\mathrm{nm})$ & Eg (eV) & Color \\
\hline \multirow{2}{*}{0.5} & 500 & $412 \pm 46$ & 3.11 & pale yellow \\
& 900 & $389 \pm 35$ & 3.21 & white \\
& 1000 & $388 \pm 33$ & 3.24 & white \\
\hline \multirow{2}{*}{0.425} & 500 & $415 \pm 47$ & 3.07 & pale yellow \\
& 900 & $390 \pm 36$ & 3.16 & white \\
& 1000 & $390 \pm 32$ & 3.20 & white \\
\hline \multirow{2}{*}{0.375} & 500 & $419 \pm 47$ & 3.09 & pale yellow \\
& 900 & $391 \pm 36$ & 3.19 & white \\
& 1000 & $393 \pm 32$ & 3.22 & white \\
\hline 0.3 & 500 & $415 \pm 44$ & 3.07 & pale yellow \\
& 900 & $393 \pm 33$ & 3.19 & white \\
& 1000 & $393 \pm 29$ & 3.21 & white \\
\hline 0 & 500 & $440 \pm 49$ & 2.92 & yellow \\
& 900 & $388 \pm 50$ & 3.19 & pale yellow \\
& 1000 & $388 \pm 43$ & 3.20 & pale yellow \\
\hline
\end{tabular}


Table 2

\begin{tabular}{ccccc}
\hline $\begin{array}{c}\text { Experimental } \\
\text { method }\end{array}$ & $\begin{array}{c}\text { Calcination } \\
\text { temperature }\left({ }^{\circ} \mathbf{C}\right)\end{array}$ & $\lambda \pm \Delta \lambda(\mathbf{n m})$ & Eg (eV) & Color \\
\hline \multirow{2}{*}{ Citrate route } & 500 & $415 \pm 44$ & 3.07 & pale yellow \\
& 900 & $393 \pm 33$ & 3.19 & white \\
\hline Glycine - & 500 & $394 \pm 39$ & 3.26 & pale yellow \\
Rhodia & 900 & $384 \pm 32$ & 3.30 & white \\
\hline \multirow{2}{*}{ HMT } & 600 & $415 \pm 57$ & 3.16 & pale yellow \\
& 900 & $384 \pm 48$ & 3.38 & white \\
\hline
\end{tabular}


Table 3

\begin{tabular}{cccc}
\hline Composition & $\mathbf{x}$ & Density & (*) \\
\hline $\mathrm{CeO}_{2}$ & 0 & 7.215 & $2.20{ }^{*}$ \\
$\mathrm{Ce}_{0.7} \mathrm{Y}_{0.3} \mathrm{O}_{1.85} \square_{0.15}$ & 0.3 & 6.560 & 2.10 \\
$\mathrm{Ce}_{0.625} \mathrm{Y}_{0.375} \mathrm{O}_{1.8125} \square_{0.1875}$ & 0.375 & 6.396 & 2.07 \\
$\mathrm{Ce}_{0.575} \mathrm{Y}_{0.425} \mathrm{O}_{1.7875} \square_{0.2125}$ & 0.425 & 6.287 & 2.05 \\
$\mathrm{Ce}_{0.5} \mathrm{Y}_{0.5} \mathrm{O}_{1.75} \square_{0.25}$ & 0.5 & 6.124 & 2.03 \\
$\mathrm{YO}_{1.5} \square_{0.5}$ & 1 & 5.032 & 1.86 \\
\hline
\end{tabular}

${ }^{*}$ refraction coefficient value for $\mathrm{CeO}_{2}\left(\mathrm{a}_{\mathrm{i}}=0.166\right)$ was determined for $\mathrm{n}=2.2$.

** densities for substituted compositions were calculated using a linear correlation from the values of $\mathrm{CeO}_{2}$ and $\mathrm{Y}_{6} \mathrm{WO}_{12}$. 